\title{
Research on Applied Undergraduate Course Reform Based on Makerspace
}

\author{
Nana Shang \\ Foshan Polytechnic \\ Foshan, Guangdong, China
}

\begin{abstract}
Applied undergraduate aims at training high quality applied talents who can adapt to economic development. In the era of "mass entrepreneurship and innovation", applied undergraduate is required to train talents with high quality of entrepreneurship and innovation. Maker Education becomes the theme. Makerspace is the subject of Maker Education. The booming of makerspace has great influence on the economy of our country. The inevitable trend of educational reform is to analyze characteristics of makerspace and reform the courses of applied undergraduate.
\end{abstract}

Keywords-makerspace; applied undergraduate; mass innovation; STEAM vocational education

\section{INTRODUCTION}

Makerspace is the combination of "Maker" and "Space" and also called "Hackspace" and "Hacklab". Makerspace plays an increasingly important role in the development of maker movement. The establishment of XinCheJian in Shanghai in 2010 begins a new chapter of the development of makerspace. In recent years, makerspace emerges continuously. In the Internet Plus era, makerspace flourishes. After the periods of "Enlightenment" 1.0 and "Entrepreneurship" 2.0, China will enter the era of "Mass Maker" 3.0 in the future five years. The maker movement will be a connecting link between the internet and traditional industries and the mass link. [1] Makerspace is of vital importance in the maker movement. We should think how to train competent talents through makerspace.

The soaring development of makerspace complies with the theme of "mass entrepreneurship and innovation". In order to train competent high quality applied talents, general colleges are guided to transform into the applied. Course reform is the key to the transformation. It is significant to bring advanced innovative ideas of makerspace in course reform of applied undergraduate and guide the course construction, in order to train high quality talents with creative spirit.

\section{CHARACTERISTICS OF MAKERSPACE}

Makerspace is a space of interactive learning and innovation with the development of maker movement and the coming of Internet Plus era, referring to a cultural form and a

This paper is the project of teaching reform in higher education of Education Department in Guangdong Province in 2015: the research result of Reform and Practice of Courses in Art and Design Major of Applied Undergraduate Based on Maker Idea. new type of learning form. As a new product of the time, makerspace integrates various resources and distributes everywhere and attracts learners, dynamically regulating learning elements.

\section{A. Cross Border}

Makerspace is a place for people to share knowledge in science, technology, digit and electronic art and realize exchange of creativity and collaborative creation. [2] The places for collaborative creation include traditional offline physical makerspace and online maker community produced with the development of internet. The "Internet Plus" effectively combines them, breaks the physical and virtual boundary and integrates various resources of makerspace.

As an important place for maker education, makerspace effectively integrates knowledge and resources required by innovation and creation for learners to practice. It breaks through limitation of traditional subjects and professional course system, integrates multidisciplinary knowledge and makes use of resources, tools and learning communities to solve problems or realize innovation and creation. In makerspace, learners make the most of multidisciplinary knowledge in physics, mathematics, electronics and art and boldly apply new thinking, new image and new methods to the reality to serve the public through advanced high-tech means like information technology, somatosensory interaction technique and 3D printing technology.

\section{B. Extensive}

Makerspace accept learners extensively. Creative people gather here, learn and share and arouse inspiration to turn ideas into reality through tools and resources in the space. Therefore, learners accepted by makerspace are extensive, referring to a learning community interested in learning, committed to innovation and willing to share.

Makerspace exists around the world. The practice of makerspace derives from the practice of Living Lab and Fab Lab. Living Lab was launched by the European Union in 2006, creating conditions and environment for users to design innovative solutions. For example, all residents in Madeira become innovative subject to create smart city (Oliveira et al., 2015). Fab Lab is a platform for low cost manufacturing experiment and rapid prototype construction. It is first proposed by Neil Gershenfeld, the director of research center for bits and atoms in MIT. The first Fab Lab was established in 
Boston in 2001. [3] The scientific and technological progress has increasingly high requirements for talents. In 2012, the American government planed to construct "makerspace" in thousand of middle and primary schools, equip digital development and manufacturing tools like open-source hardware, 3D printer and laser cutting machine. On the first White House Make Faire in 2014, the former president Obama called on, "All citizens join in the action of inspire innovation and encouragement of community invention". (White House, 2014) In 2009, the makerspace of our country began to develop, forming maker ecosphere with Beijing Makerspace, Shanghai XinCheJian and Shenzhen 2015 Chaihuo Maker Space as centers. On Jan. 4, 2015, Premier Li Keqiang visited Shenzhen Chaihuo Maker Space so it attracts more people's attention. Innovation is required by the development of times. Educational ideas should be timely updated to train innovative talents. Makerspaces are brought in schools like makerspace in Tsinghua University, makerspace in Tongji University, makerspace in Southwest Jiaotong University and makerspace in Wenzhou University. According to the statistics from makerspace website, 1,929 renowned makerspaces have been established worldwide by June 2015. Makerspace extensively influences the ideas of talent cultivation. It is inevitable and new reform to bring makerspace in the education system.

\section{Dynamic}

Makerspace are open to people with consciousness of innovation and sharing. Learners can learn in makerspace at anytime. The dynamic learning community strengthens the diversified influence of learning. Makerspace provides learners with a platform for interactive learning and sharing. Therefore, it is not static but dynamic space that learners update space and knowledge continuously in mutual support. In makerspace, the knowledge acquisition is open, so is the learners' learning process. Learners can search knowledge and raise questions and understanding to enrich knowledge of the makerspace. Different from the traditional fixed learning place, physical facilities in makerspace can change according to learners' activities. Compared with chemical laboratory and physics laboratory in school education, maker laboratory has wider and opener space, diversified equipment and materials for many purposes. [4] The makerspace is learner-centered for creation, collaboration and sharing. Learners can learn creatively with the help of equipment. Learners learn from each other and dynamically realize sustainable learning.

\section{SELECTION OF CONTENTS IN APPLIED UNDERGRADUATE COURSE BASED ON MAKERSPACE}

In the period of mass higher education, except for a few top universities, most colleges should train applied or skilloriented talents. [5] American scholar Brubaker thinks the logical starting point of higher education is profound knowledge. Confucianism plays an important role in the educational development of our country. Confucian school lays particular emphasis on research of rationalistic philosophy. Mohist thought that focuses on research of application practice declines. Research of profound knowledge with rationalism gathers in official school. The pragmatic teaching uses apprenticeship system in family workshop to train talents.
Under the impact of industrial revolution, it is difficult for apprenticeship system in family workshop to meet the requirements of social development for plenty of labors so it suffers from great blow. In the 1990s, with the industrialization reform and rapid economic development, our country had increasingly high requirements for skilled talents. Some secondary technical schools to train applied talents on the first production line appear to meet the demands of economic development. Secondary technical schools have no channel to reach the undergraduate level and fail to form systems to train applied talents. Undergraduate colleges still focus on academic research. In March 2014, the Vice Minister of Education Lu Xin addressed on China Development Forum that "More than six hundred local undergraduate colleges will transform into application-oriented and vocational education". On October 21, 2015, the Opinions on Guiding the Transformation of Local Undergraduate Colleges into Applied Colleges issued by the Ministry of Education, the National Development and Reform Commission and the Ministry of Finance guide the transformation of colleges into applied undergraduate, in order to meet the demands of times with "mass entrepreneurship and innovation" for innovative applied talents and promote the change from "Made in China" to "Created in China".

Generally speaking, course contents involve two kinds of knowledge: the "propositional knowledge" related to facts, concepts, rules and principles and the "procedural knowledge" related to experience and strategy. "Facts and concepts" answer "what it is"; "understanding and principle" answer "why"; "experience" answers "how to do"; "strategy" answer "how to do better". [6] Course contents directly influence the teaching and learning effects of educator and educatee. From the perspective of training objectives, applied undergraduate is the education leading to work system. Therefore, the course contents of applied undergraduate should involve knowledge and skills used in work.

\section{DECONSTRUCTION AND RECOMBINATION OF APPLIED UNDERGRADUATE COURSES BASED ON MAKERSPACE}

Applied undergraduate especially newly transformed ones still use subject system to organize courses. According to the educational system, applied undergraduate and academic undergraduate are parallel education systems. The system of vocational education includes secondary vocational school, higher vocational school and applied undergraduate, covering undergraduate, graduate and doctoral students and corresponding to research-based education system. Vocational education leads to work system and directly serves or creates work. In order to train high level talents with innovation spirit and ability, applied undergraduate must break through the limitation of traditional courses and recombine courses according to the demands of innovative talent training.

The concepts of "makerspace" contain three levels: (1) Environment level refers to the atmosphere to share resources; (2) Spiritual level refers to life idea of collaboration, sharing and creation instead of resources and spaces; (3)Function level promotes skill learning and human knowledge innovation. [7] The training of innovative talents is systematic and requires collaboration of innovative cultural environment, courses, 
learning forms, teachers, educational organization and teaching plan. It is an important tendency in course reform of "mass entrepreneurship and innovation" era to reform contents and structures of applied undergraduate courses through makerspace. We should deeply dig the above-mentioned three levels and optimize the current course system to meet learners' demands.

Applied undergraduate course should free from the traditional subject system and build study modules with knowledge in the makerspace for learners. Generally speaking, there are two ways of ordering: the constitution theory and the generation theory. The constitution theory means ordering the knowledge contents according to the subject system on physical meaning, emphasizing the "mechanical" objective construction of knowledge by static and lifeless "object"; the generation theory means ordering according to the action system on biological meaning, emphasizing the "organic" subjective building of knowledge by dynamic and animate "subject". [8] In makerspace, learners can anew "organically" build knowledge module in the "subject" of learning to solve problems and acquire learning methods. Meanwhile, they can share learning package built by them in makerspace to enrich the course system and improve comprehensive quality like communication skills, teamwork spirit and language expression ability. Course systems are created continuously in collaboration of learners. Maker course is not a course but a series of progressive course combination. Introductory courses can pay attention to the teaching of basic subject knowledge and training of operating skill related to electronics, machinery, materials and computer; intermediate courses can focus on training of complicated skills like 3D modeling, manufacturing, circuit assembly, electronic cutting and advanced programming; advanced courses can conduct comprehensive innovation practice and let students create new schemes and products collaboratively in groups according to real projects and problems. [4] Makerspace is the main carrier of maker course. The combination of maker courses sets a good example for the reform of applied undergraduate courses. The subject course system should be deconstructed according to STEAM course development idea including Science, Technology, Engineering, Arts and Mathematics. Knowledge module consisting of science, technology, engineering, arts and mathematics is built through electronics, machinery, materials and computer. Each knowledge module has introductory, intermediate and advanced levels. Learners are free to choose learning module and levels of it in the makerspace according to their needs.

The trans-boundary nature of makerspace meets the demands in deconstruction and recombination of applied undergraduate courses. A famous German vocational education expert Professor Paetzold observes, "It seems courses build a bookshelf in storage and reappearance of experience and knowledge. The layering of bookshelf makes it easier to order and recover and greatly eases the burden of memory. Therefore, the memory of school courses has universal instead of individual significance. A culture contained in school course makes the interlayer of memory spread culture easier through teaching. It is more necessary to seize a sequence pattern of methodology teaching for more compound culture and extensive knowledge. In the compound culture, exchange involving sequence will become the basic condition of action capability". [9] In order to train compound talents with creative spirit, applied undergraduate must take work system, innovation and creation as standards of course reform. The makerspace is a creative compound culture and a dynamic bookshelf for storage and reappearance of experience and knowledge and generate knowledge system when learners solve practical problems.

\section{CONCLUSION}

Applied undergraduate courses based on makerspace break the limitation for learners by single space and thread. Learners can carry out multithreading learning anytime and anywhere. They can learn personalized courses and make the most of resources and save course resources. Learners are users as well as developers of courses who can become makers through combination of learning and doing.

\section{REFERENCES}

[1] Luo Bing. China Maker 3.0: China Enters the "Mass Maker" Era in the Future Five Years [N], Science and Technology Daily, Apr.23, 2015 (the eighth edition)

[2] Shen Ping. Construction of "Makerspace" in College Libraries [J], Modern Information, 2014(9): 158-161

[3] Luo Liang, Zhu Zhiting. Open-source Hardware: Promote Maker Education Practice [J], China Educational Technology, 2015(4): 7-14

[4] Yang Xianmin, Li Jihong. Value Potential and Controversy of Maker Education [J], Modern Distance Education Research, 2015(2): 23-34

[5] Pan Maoyuan. Orientation of Applied Undergraduate Colleges [J], Exploring Education Development, 2007, (7): 34-36

[6] Jiang Dayuan. Discussion on Action System and CharacteristicsThinking on Course System of Vocational Education [J], Exploring Education Development, 2002, (12): 70-75

[7] Tao Lei. Research on Construction of Makerspace in Library [J], Library and Information Service, 2013 (14): 72-76

[8] Jiang Dayuan. Deconstruction of Subject System and Reconstruction of Action System [J], Educational Research, 2005(8): 53-57

[9] Guenter Paetzold: Lernfelder-Lernkooperation, Neugestaltung beruflicher Bildung, Projekt Verlag, Dortmund, 2002. 